\section{Biological Passports! Only half the story!}

Androgenic-anabolic steroids (AAS) are still the most frequent adverse analytical findings in- and out-of-competition. Increased out-of-competition testing helps to combat the cheat who is using short-acting preparations and ceasing administration prior to competition in anticipation of testing.

In the field of drug control in sport, designer drugs can be considered as ones that are manufactured specifically to circumvent the doping tests, i.e. they are supplied in clandestine fashion and are not compounds that are advertised for the bodybuilding market. The attempted use of such has become a covert science in direct competition with advances in detection methods. This indicates a deliberate involvement of quasimedical and even governmental agencies, in the promotion of drug abuse in sport. Classified documents saved after the collapse of the German Democratic Republic revealed that since 1983 a pharmaceutical company had produced parenteral preparations of epitestosterone propionate exclusively for the governmental doping programme [1]. Epitestosterone is a steroid with no anabolic activity, but its administration with testosterone simultaneously or sequentially enables an athlete to manipulate the test for testosterone administration if the test is based solely on determination of a raised testosterone/epitestosterone (T/E) ratio. One percent of testosterone is excreted unchanged, apart from conjugation to glucuronic acid, compared with $\sim 30 \%$ of epitestosterone, and the T/E ratio approximates unity normally, but is raised in testosterone users. However, administration of these steroids in a ratio of $\sim 30: 1 ; \mathrm{T} / \mathrm{E}$, e.g. as parenteral or oral (undecanoate ester) preparations will elevate plasma testosterone, but will not augment the T/E ratio, (although the urinary $\mathrm{T} /$ luteinizing hormone $(\mathrm{LH})$ ratio will be raised following testosterone administration [2]. More crudely, epitestosterone could simply be swallowed in anticipation of a drug test or even attempts be made to urinate over a finger that surreptitiously has epitestosterone residue on the surface. In an effort to counter such strategies, World Anti-Doping Agency (WADA) has set a urinary threshold of $200 \mu \mathrm{g} / \mathrm{L}$ for epitestosterone. The Bay Area Laboratory Cooperative (BALCO) affair, in California, USA, attracted media attention due to the high profile of the athletes involved, not least because of a transdermal preparation ('The Cream') was supplied containing testosterone and epitestosterone, as well as a sublingual preparation of a new anabolic steroid Tetrahydrogestrinone (THG), coded as 'The Clear' [3].

In the case of a T/E ratio $>4$, a reliable method of detection (e.g. isotope ratio mass spectrometry [IRMS]) has not determined the exogenous source of the substance, further investigations may be conducted to ascertain whether a doping offence has occurred. Usually it is concluded that surreptitious testosterone administration has happened, but occasionally the athlete may

\author{
Michael R. Graham ${ }^{1}$, \\ Bruce Davies², \\ Julien S. Baker ${ }^{3}$
}

\section{Michael R. Graham, Llantarnam Research Academy, Newport Road, Llantarnam, Cwmbran, NP44 3AF, UK. \\ 2 Bruce Davies, Health and Exercise Science Department, University of South Wales, CF37 1DL, UK \\ 3 Julien S Baker, Director of Research, Institute of Clinical Exercise and Health Science, Exercise Science Research Laboratory, School of Science, University of the West of Scotland, Hamilton, Lanarkshire, Scotland, ML3 OJB, UK.}

\section{Corresponding author:} Michael R. Graham

\section{झ drmirograham@icloud.com}

\begin{abstract}
Llantarnam Research Academy, Newport Road, Llantarnam, Cwmbran, NP44 3AF, UK
\end{abstract}

Citation: Graham MR, Davies B, Baker JS. Biological Passports! Only half the story!. J Drug Abuse. 2015, 1:1.

have a physiologically increased ratio, being a 'natural biological outlier' [4]. In addition, the possibility of a pathological condition, e.g. a T-secreting tumour accounting for an augmented ratio in a sports competitor must not be neglected, although there is no such case report described in the scientific literature (possibly because such tumours are most likely to be of testicular origin and that these also secrete epitestosterone). With an adverse finding, investigating the T/E results from previous and subsequent tests, i.e. assessing the $T / E$ intra-individual (within-subject) variability, is useful in determining whether an offence has occurred. However, to date, there are very limited data on intra-individual variation of $\mathrm{T} / \mathrm{E}$ ratios presented in the peer-reviewed literature. In their article on detection of testosterone and xenobiotics, Catlin et al. [5] have reviewed the data on intra-individual variability. They present their criteria for determining whether testosterone doping has occurred in men, based on T/E ratio data from drug free males who showed an intra-individual coefficient of variation (CV) of $<60 \%$ (variation from the collection of three or more samples of urine taken at monthly or greater intervals). In contrast 
they report an example of a case of an athlete with an initial T/E ratio of 8.2, and after being sampled four times had a CV of $114 \%$, indicating that testosterone administration had occurred. This pattern was considered to be typical of an individual who is caught and then discontinues testosterone administration. In these authors' experience, most testosterone users who provide three or more urine samples have a CV of $>60 \%$. In 1997, individuals with a CV $<60 \%$ and a T/E ratio between 6 and 10, were tentatively classified as 'naturally increased' Catlin et al. [5]. WADA in their Technical Document [6] stated that "normal variation of up to $30 \%$ in males and $60 \%$ in females may be expected" and that "using appropriate statistical evaluation is found to be significantly different, that will constitute a proof of the administration of a source of testosterone." In the event that previous T/E results are not available three further unannounced tests should be carried out, preferably within a 3-month period following the report of the suspicious analytical result.

Currently any T/E level $>4: 1$ is considered abnormal.

The recent publication by Baume et al. [7], a retrospective urinalysis of the T/E ratio of 4195 urine samples of 879 professional footballers over a five year period from 20082013, and was not under strict research conditions and used 32 different laboratories. The results were no different from the general populous [8].

Despite some anomalies not one sample of urine was analysed for exogenous androgenic-anabolic steroids and all the samples have now conveniently been destroyed [7]. The mean CV was $46 \%$, which was outside the recommended figure of $30 \%$ (WADA Technical Document -TD2004EAAS)

Interestingly one sample contained neither testosterone nor epitestosterone, which suspiciously suggests that tap water was substituted for urine. Another sample which had a T/E ratio $<4: 1$ had a CV of $187 \%$. The mean T/E ratio in the Baume et al. [7] study was 1.37:1 and 1.35:1 in-competition and out-of-competition testing, which was not significantly different from the study by van Renterghem et al. [8].

However, the pressure to get into the top division suggests that the problem may be even more prevalent in lower divisions because the players may be taking performance enhancing drugs to make the step up.

UEFA says in the past three seasons its anti-doping programme has secured two positive drug samples from 2,000 tests.

An allegation has been made that the number of dopers being caught is significantly lower than the proportion which UEFA's study suggests may be cheating [9].

UEFA have stated that it impossible to draw definitive conclusions from the study by Baume et al. [7]. It added that the results may have been affected by confounding factors such as alcohol use, the lack of standardised procedures at laboratories and the failure to conduct a second analysis on the samples.

Many questions remain unanswered. The authorities are under scrutiny to identify and eliminate cheats and create a level playing field. However, there appear to be a multitude of factors, not least of which is financial limitation, which is preventing any and all doping sportspersons from being identified and brought to book.

The biological passport, which is currently used in athletics, can only assist such identification in other semi- and full-contact sports, such as football, rugby and combat sports. 


\section{References}

1 Franke WW, Berendonk B (1997) Hormonal doping and androgenization of athletes: a secret program of the German Democratic Republic government. Clinical Chemistry 43: 1262-1279.

2 Kicman AT, Brooks RV, Collyer SC, Cowan DA, Nanjee MN, et al. (1990) Criteria to indicate testosterone administration. British Journal of Sports Medicine 24: 253-264.

3 Catlin DH, Sekera MH, Ahrens BD, Starcevic B, Chang YC, et al. (2004) Tetrahydrogestrinone: discovery, synthesis, and detection in urine. Rapid Communications in Mass Spectrometry 18: 1245-1249.

4 Garle M, Ocka R, Palonek E, Björkhem I (1996) Increased urinary testosterone epitestosterone ratios found in Swedish athletes in connection with a national control programme: evaluation of 28 cases. Journal of Chromatography 687: 55-59.

5 Catlin DH, Hatton CK, Starcevic SH Issues in detecting abuse of xenobiotic anabolic steroids and testosterone by analysis of athletes' urine. Clinical Chemistry 43: 1280-1288.

6 https://wada-main-prod.s3.amazonaws.com/resources/files/ WADA-TD2004-EAAS-Reporting-and-Evaluation-Guidance-forTestosterone,-Epitestosterone,-T-E-Ratio-and-Other-EndogenousSteroids.pdf

7 Baume N, Geyer H, Vouillamoz M, Grisdale R, Earl M, et al. (2015) Evaluation of longitudinal steroid profiles from male football players in UEFA competitions between 2008 and 2013. Drug Testing and Analysis.

8 Van Renterghem P, Van Eenoo P, Geyer H, Schanzer W, Delbeke FT (2010) Reference ranges for urinary concentrations and ratios of endogenous steroids, which can be used as markers for steroid misuse, in a Caucasian population of athletes. Steroids 75: 154-163.

9 http://www.thesundaytimes.co.uk/sto/news/uk_news/ thedopingscandal/article1609608.ece 